J. Lake Sci. (湖泊科学), 2015, 27(3):527-534

http://www. jlakes. org. E-mail : jlakes@niglas.ac.cn

(C) 2015 by Journal of Lake Sciences

\title{
湖光岩玛珥湖春季浮游植物对溶解态氮的吸收"
}

\author{
张国维 $^{1}$, 李长玲 ${ }^{1 * *}$, 黄翔鹄 ${ }^{1}$, 古滨河 $^{2}$ \\ (1:广东海洋大学水产学院, 湛江 524088 ) \\ ( 2 : 美国佛罗里达大学土壤和水科学系,佛罗里达州 32611)
}

\begin{abstract}
摘 要: 利用 ${ }^{15} \mathrm{~N}$ 稳定同位素示踪技术, 采用现场挂瓶培养的方法测定了湖光岩玛珥湖浮游植物群落对铵态氮、硝态氮和 尿素态氮的吸收速率, 研究了湖光岩玛珥湖浮游植物群落氮吸收及其吸收动力学特征. 结果表明: 湖光岩玛珥湖共检测 到浮游植物 7 门 54 种 (包括变种和变型), 主要为蓝藻门、硅藻门和绿藻门种类, 分别占浮游植物总量的 $44.68 \%$ 、 $26.70 \%$ 和 $19.21 \%$, 其中水华微囊藻 (Microcystis flos-aquae) 与铜绿微囊藻 (Microcystis aeruginosa) 为绝对优势种, 优势度分 别为 0.39 与 0.28 . 湖光岩玛珥湖浮游植物群落对铵态氮的绝对吸收速率最高, 分别是对硝态氮、尿素态氮绝对吸收速率 的 5.8 和 4.2 倍, 占 3 种溶解态氮总吸收量的 $73.3 \%$. 铵态氮、硝态氮和尿素态氮的相对优先指数分别为 $2.907 、 0.190$ 和 1.192 , 说明浮游植物群落优先吸收铵态氮, 其次为尿素态氮, 最后为硝态氮. 铵态氮、硝态氮和尿素态氮的周转时间分别为 3.72 .57.03 和 $9.07 \mathrm{~h}$. 湖光岩玛珥湖浮游植物对溶解态氮的吸收可用 Michaelis-Menten 酶动力学方程描述, 最大比吸收速 率表现为铵态氮 $>$ 尿素态氮 > 硝态氮, 亲和力表现为硝态氮 $>$ 铵态氮 $>$ 尿素态氮. 湖光岩玛珥湖浮游植物群落对铵态氮 具有较高的吸收潜力, 并且对硝态氮具有一定的亲和力,具备利用硝态氮的能力.
\end{abstract}

关键词: 湖光岩玛珥湖; 浮游植物; 稳定同位素; 氮吸收; 吸收动力学

\section{Uptake of dissolved nitrogen by phytoplankton in spring in Huguangyan Maar Lake}

\author{
ZHANG Guowei ${ }^{1}$, LI Changling ${ }^{1}$, HUANG Xianghu ${ }^{1} \&$ GU Binhe ${ }^{2}$ \\ (1: Fisheries College, Guangdong Ocean University, Zhanjiang 524088, P. R. China) \\ (2: The Soil and Water Science Department, University of Florida, Florida 32611, USA)
}

Abstract: Using ${ }^{15} \mathrm{~N}$ stable isotope tracer technique by adopting the in-situ flask culture, the uptake rates of ammonium, nitrate and urea by phytoplankton community were measured in Huguangyan Maar Lake, in order to characterize the nitrogen absorption and the characteristics of absorption kinetics by phytoplankton community in spring in the lake. The results showed that there were 54 species (including varieties and forms belonging to 7 phyla) of phytoplankton in the lake, mainly from the Cyanophyta, Bacillariophyta and Chlorophyta, which accounted for $44.68 \%, 26.70 \%$ and $19.21 \%$, respectively. Microcystis flos-aquae and M. aeruginosa were the absolute dominant species, and the dominance indexes were 0.39 and 0.28 , respectively. Uptake rate of ammonium of phytoplankton community was the highest, about 5.8 times of nitrate, 4.2 times of urea, and accounted for $73.3 \%$ of the total nitrogen uptake of the three kinds of dissolved nitrogen. The relative preference indices for ammonium, nitrate and urea were $2.907,0.190$ and 1.192 , respectively. Phytoplankton communities prefer uptaking ammonium, followed by urea, and finally nitrate. The turnover time for ammonium, nitrate and urea were $3.72,57.03$ and $9.07 \mathrm{~h}$, respectively. Nitrogen uptake kinetics of phytoplankton community agree with Michaelis-Menten equation. The maximum uptake rate was ammonium $>$ urea $>$ nitrate, and affinity $(1 / K \mathrm{~s})$ was nitrate $>$ ammonium $>$ urea. Phytoplankton community of the Huguangyan Maar Lake has a high absorption potential of ammonium, and a certain affinity to nitrate, therefore, the lake has the ability to use nitrate.

Keywords: Huguangyan Maar Lake; phytoplankton; stable isotope; nitrogen uptake; absorption kinetics

湖光岩玛珥湖 $\left(21^{\circ} 09^{\prime} \mathrm{N}, 110^{\circ} 17^{\prime} \mathrm{E}\right)$ 是雷琼新生代火山区中一个典型的玛珥湖, 位于中国广东省湛江市

* 广东省科技攻关项目(2010B060200011) 和广东省自然基金项目 (9152408801000003) 联合资助. 2014 - 03-08 收 稿;2014-10-08 收修改稿. 张国维(1988 ), 男, 硕士研究生; E-mail: twzhangguowei@ 126. com.

** 通信作者;E-mail:ybc1901@ 126. com. 
西南方约 $18 \mathrm{~km}$ 处 (图 1), 属于热带季风气候区, 年均气温 $23^{\circ} \mathrm{C}$, 其汇水面积为 $32 \mathrm{~km}^{2}$, 平均水深约为 $12 \mathrm{~m}$, 最大深度约为 $22 \mathrm{~m}^{[1]}$. 湖光岩玛珥湖是由平地火山爆发后冷却下沉形成的玛珥式火山湖, 湖水的变化主要 取决于降水和地下水, 是一个典型的亚热带湖泊, 也是世界上最大的玛珥湖, 可作为研究玛嵦湖现代生态学 的理想场所. 由于湖光岩玛珥湖是一个封闭式、面积小、结构简单的稳定的生态系统, 自然环境独特, 水体生 态环境良好, 浮游植物群落结构多样, 通过浮游植物对溶解态氮的吸收转化作用完成湖泊氮素的生物循环 和水质净化.

氮素的生物地球化学循环是整个生物圈物质循环的重要组成部分, 在湖泊营养循环中占有重要地 位 ${ }^{[2]}$. 氮循环包括地球化学循环和生物循环, 浮游植物是湖泊生态系统氮生物循环的主要承担者, 也是生物 地球化学循环的关键环节. 有研究表明, 湖泊生态系统中氮营养物主要通过微生物的作用去除 ${ }^{[3]}$, 而浮游植 物的作用也是必不可少的, 它们为好氧型微生物的硝化作用提供充足的氧气和良好的微生态环境, 同时也 直接吸收利用部分溶解态氮用于自身生长 ${ }^{[4]}$. 浮游植物作为水域生态系统中的初级生产者, 是整个水域生 态系统中物质循环和能量流动的基础, 其对水体营养状态的变化能迅速做出响应 ${ }^{[5]}$. 溶解态氮是浮游植物 吸收氮的主要形式,但不同形态氮的吸收特征因浮游植物群落组成和环境条件不同而存在差异 ${ }^{[6]}$.

浮游植物对溶解态氮的吸收, 是湖泊生态系统氮循环的重要环节 ${ }^{[7]}$. 国外对湖泊等水域生态系统浮游 植物氮吸收的相关研究较多 ${ }^{[8-10]}$, 而国内的相关研究较少 ${ }^{[7,11-13]} . \mathrm{Gu}$ 等 ${ }^{[9-10]}$ 利用 ${ }^{15} \mathrm{~N}$ 同位素示踪技术, 对美国 Smith、Okeechobee 等湖泊中浮游植物氮吸收开展了研究, 揭示了浮游植物氮吸收的相关机理及其动力学特 征; 在国内,杨柳等 ${ }^{[7]}$ 利用 ${ }^{15} \mathrm{~N}$ 同位素示踪技术研究了太湖的浮游植物群落对不同形态氮的吸收速率特征. 目前, 玛珥湖研究主要集中在沉积与环境方面,而关于湖光岩玛珥湖浮游植物氮吸收的研究尚无相关报道. 因此, 本文利用稳定同位素示踪技术, 研究浮游植物群落对溶解态氮的吸收及其动力学特征, 了解浮游植物 在氮循环中的作用规律, 以期为湖光岩玛珥湖氮素生物循环的研究提供基础资料.

\section{1 材料与方法}

\section{1 采样}

根据湖光岩玛珥湖生态系统稳定并且相对封闭的水文条件, 本研究共设 6 个采样点 (图 1) 用于分析湖 光岩玛珥湖浮游植物群落组成特征, 并选择 S4 点位进行稳定同位素示踪技术测定浮游植物氮吸收实验. 采 样于 2013 年 5 月 $12 、 13$ 日进行, 用 $2.5 \mathrm{~L}$ 有机玻璃采水器采集水面下 $0.5 \mathrm{~m}$ 深水样进行现场培养实验. 同时 采水样 $500 \mathrm{ml}$ 装人采样瓶中, 用于测定水化指标. 另采集 $1 \mathrm{~L}$ 水样, 加 $15 \mathrm{ml}$ 鲁哥试剂固定, 用于浮游植物群 落组成分析. 采样的同时, 用 YSI 650 MDS 型多参数水质监测仪 (美国) 测定采样水深处的温度 $(\mathrm{T}) 、 \mathrm{pH}$ 值、 溶解氧 (DO) 等指标, 透明度 (SD) 用塞氏盘测定. 测定氮吸收的浮游植物水样用 $180 \mu \mathrm{m}$ 的绢网过滤除去大 型浮游动物和碎屑, 以排除对氮吸收的干扰 ${ }^{[7]}$.

\section{2 水化指标测定与浮游植物分析}

水样用孔径为 $0.45 \mu \mathrm{m}$ 的醋酸纤维滤膜抽滤后, 滤膜用于叶绿素 a 测定, 水样用于总溶解态氮、总溶解 态磷、铵态氮、硝态氮、尿素等测定. 其中总溶解态氮、总溶解态磷测定采用过硫酸盐氧化法 ${ }^{[14]}$, 尿素测定采 用二乙酰一肜法 ${ }^{[15]}$, 铵态氮采用靛酚蓝分光光度法 ${ }^{[16]}$, 硝态氮采用紫外分光光度计比色法 ${ }^{[14]}$. 浮游植物叶 绿素 $\mathrm{a}$ 含量测定采用丙酮萃取分光光度法 ${ }^{[17]}$. 浮游植物计数采用计数框行格法, 浮游植物种类鉴定参照文 献 $[18]$.

\section{3 氮吸收实验}

测定浮游植物对不同形态氮的吸收速率, 采用挂瓶的方法, 在 $\mathrm{S} 4$ 点位采集 $0.5 \mathrm{~m}$ 深处水样进行原位挂 瓶, 将 $1 \mathrm{~L}$ 水样加人 $1.1 \mathrm{~L}$ 透明聚乙烯培养瓶, 再分别加人 3 种不同形态的氮稳定同位素示踪剂 $\left({ }^{15} \mathrm{~N}^{-} \mathrm{NH}_{4} \mathrm{Cl}\right.$ 、 $\left.{ }^{15} \mathrm{~N}-\mathrm{NaNO}_{3} 、{ }^{15} \mathrm{~N}-\mathrm{Urea}\right)$, 示踪剂丰度均为 $98 \%$ (98\% atom ${ }^{15} \mathrm{~N}$, Sigma-Aldrich), 在对应深度进行挂瓶培养. 同 时挂 3 个不添加同位素的空白瓶用来测定浮游植物的氮同位素自然丰度. 添加的 ${ }^{15} \mathrm{~N}$ 稳定同位素浓度要小

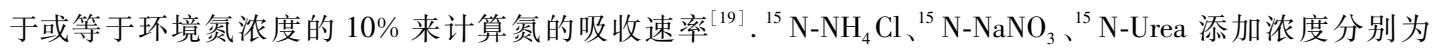
$0.05 、 0.10 、 0.05 \mu \mathrm{mol} / \mathrm{L}$, 挂瓶 $4 \mathrm{~h}$ 后向瓶中加人饱和氯化录溶液终止实验 ${ }^{[10]}$. 带回实验室, 用预先在 $450^{\circ} \mathrm{C}$ 马弗炉中灼烧 $3 \mathrm{~h}$ 的 Whatman $\mathrm{GF} / \mathrm{C}$ 滤膜抽滤, 再抽滤 $10 \mathrm{ml}$ 去离子水以清洗掉吸附在滤膜上的示踪剂. 过 
滤后的膜放人 $70^{\circ} \mathrm{C}$ 的烘箱中, $48 \mathrm{~h}$ 后称 重 $^{[7]}$. 最后用刀片刮下浮游植物, 用 Pressed Tin Capsules $5 \mathrm{~mm} \times 9 \mathrm{~mm}$ 锡囊包装, 藻体中 $\delta^{15} \mathrm{~N}$ 和颗粒态氮 (PN) 由美国华盛顿州立大 学实验室采用 CF-ZRMS 稳定同位素比例质 谱仪 ( GV instruments Isoprime, Manchester, UK) 测定.

参照如下公式,计算氮吸收特征参数.

比吸收速率 $V\left(\mathrm{~h}^{-1}\right)^{[20]}$ 为:

$$
V=\frac{{ }^{15} \mathrm{~N}_{\mathrm{S}}-{ }^{15} \mathrm{~N}_{\mathrm{n}}}{\left({ }^{15} \mathrm{~N}_{\mathrm{enr}}-{ }^{15} \mathrm{~N}_{\mathrm{n}}\right) \cdot T}
$$

式中, ${ }^{15} \mathrm{~N}_{\mathrm{S}}$ 为实测样品的 ${ }^{15} \mathrm{~N}$ 丰度, ${ }^{15} \mathrm{~N}_{\mathrm{n}}$ 为浮 游植物 ${ }^{15} \mathrm{~N}$ 的天然丰度 $(0.366 \%),{ }^{15} \mathrm{~N}_{\mathrm{enr}}$ 为加 人示踪剂后培养介质初始 ${ }^{15} \mathrm{~N}$ 丰度, $T$ 为培养 时间 ( h ).

绝对吸收速率 $\rho(\mu \mathrm{mol} /(\mathrm{L} \cdot \mathrm{h}))^{[20]}$ 为:

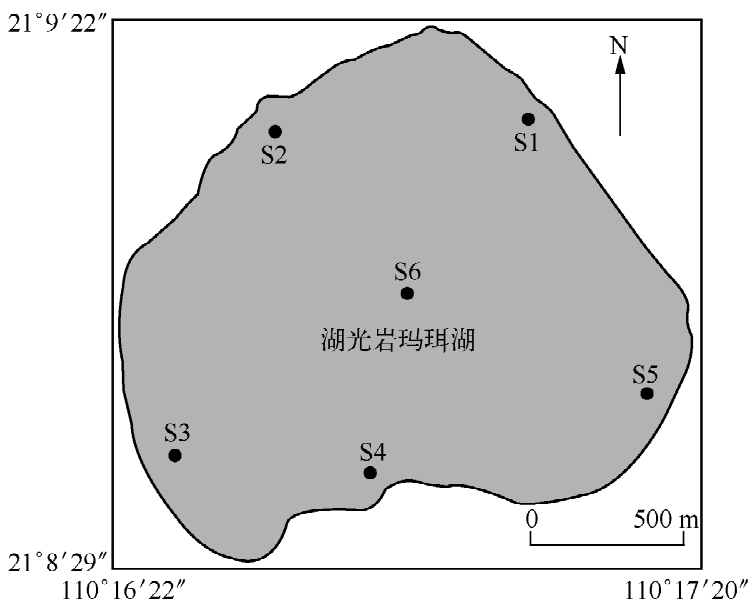

图 1 湖光岩玛珥湖及采样点位置 Maar Lake and coring site

$$
\rho=V \cdot \mathrm{PN}
$$

相对优先指数 $R P I^{[7,20]}$ 、周转时间 $T T(\mathrm{~h})^{[21]}$ 为:

$$
\begin{gathered}
\operatorname{RPI}\left(\frac{\mathrm{NH}_{4}^{+}}{\mathrm{DN}}\right)=\frac{\rho\left(\mathrm{NH}_{4}^{+}\right)}{\rho(\mathrm{DN})} / \frac{\left[\mathrm{NH}_{4}^{+}\right]}{[\mathrm{DN}]} \\
T T\left(\mathrm{NH}_{4}^{+}\right)=\frac{\left[\mathrm{NH}_{4}^{+}\right]}{\rho\left(\mathrm{NH}_{4}^{+}\right)}
\end{gathered}
$$

式中, $\rho\left(\mathrm{NH}_{4}^{+}\right)$为浮游植物群落对铵态氮的绝对吸收速率, $\rho(\mathrm{DN})$ 为浮游植物群落对铵态氮、硝态氮和尿素 态氮绝对吸收速率之和. [ $\left.\mathrm{NH}_{4}^{+}\right]$为培养介质中铵态氮浓度, $[\mathrm{DN}]$ 为培养介质中铵态氮、硝态氮、尿素态氮浓 度之和. $R P I\left(\mathrm{NO}_{3}^{-} / \mathrm{DN}\right) 、 R P I(\mathrm{Urea} / \mathrm{DN})$ 计算公式与 $R P I\left(\mathrm{NH}_{4}^{+} / \mathrm{DN}\right)$ 类似, $T T\left(\mathrm{NO}_{3}^{-}\right) 、 T T(\mathrm{Urea})$ 的计算公式 与 $T T\left(\mathrm{NH}_{4}^{+}\right)$类似.

\section{4 氮吸收动力学实验}

吸收动力学实验采用浓度梯度法 ${ }^{[10]}$. 采集 $0.5 \mathrm{~m}$ 深处水样 $1 \mathrm{~L}$ 加人透明聚乙烯培养瓶, 再加人 3 种不同 形态的氮稳定同位素示踪剂, 进行现场挂瓶实验. 示踪剂浓度梯度为 $0.05 、 0.1 、 0.5 、 1.0 、 2.0 、 5.0$ 、 $10.0 \mu \mathrm{mol} / \mathrm{L}$, 每种形态氮设置 3 个重复. 示踪剂浓度梯度代表的是 $\mathrm{N}$ 原子的摩尔浓度,一分子 Urea 含有两 个 $\mathrm{N}$ 原子, 因而 Urea 的添加浓度为以上浓度的一半 ${ }^{22]}$. 实验方法同 1.3 .

利用米氏 (Michaelis-Menten) 方程的 Lineweaver-Burk plot 法,将 $1 / V$ 对 $1 /[S]$ 作图回归计算米氏常数 $\left(K_{\mathrm{S}}\right)$ 与最大比吸收速率 $\left(V_{\text {max }}\right)$, 并通过对数作图进行吸收动力学曲线拟合.

$$
V=\frac{V_{\max } \cdot S}{K_{\mathrm{S}}+S}
$$

式中, $S$ 为底物浓度 $(\mu \mathrm{mol} / \mathrm{L})$.

\section{2 结果}

\section{1 浮游植物群落组成与环境特征}

共检测到湖光岩玛珥湖浮游植物 7 门 54 种 (包括变种和变型), 主要为蓝藻门、硅藻门和绿藻门, 分别 占 $44.68 \%$ 、26.70\% 和 $19.21 \%$ (图 2). 各点位浮游植物丰度范围为 $8.3 \times 10^{4} \sim 20.7 \times 10^{4} \mathrm{cells} / \mathrm{L}$. 主要种类 
有水华微囊藻 (Microcystis flos-aquae)、铜绿微囊藻 (Microcystis aeruginosa)、微小色球藻 (Chroococcus minutus)、颗粒直链藻 (Melosira granulata) 、小球藻 (Chlorella vulgaris) 等, 其中水华微囊藻与铜绿微囊藻为绝对优 势种, 优势度分别为 0.39 与 0.28 .

研究样点的水温约为 $30^{\circ} \mathrm{C}, \mathrm{pH}$ 值为 $7.83 \sim 8.10$, 溶解氧浓度范围为 $6.82 \sim 7.05 \mathrm{mg} / \mathrm{L}$, 透明度为 $370 \mathrm{~cm}$. 光照、温度与 $\mathrm{pH}$ 等环境条件适合浮游植物的生长, 春季浮游植物群落结构组成较为复杂. 叶绿素 $\mathrm{a}$ (Chl. a) 含量均值为 $2.76 \mu \mathrm{g} / \mathrm{L}$, 应用卡尔森营养状态指数 (TSI) 对研究水域水体营养状态进行评价, 其叶绿 素 a 分指数 $T S I_{\mathrm{M}}$ (Chl. a) 为 35.7 , 按照 $T S I$ 指数在 37 以下为贫营养的标准 ${ }^{[23]}$, 湖光岩玛珥湖在春季表现出 贫营养特征. 本研究表明湖光岩玛珥湖不同采样点位的浮游植物群落组成与理化因子差异较小, 生态系统 稳定.

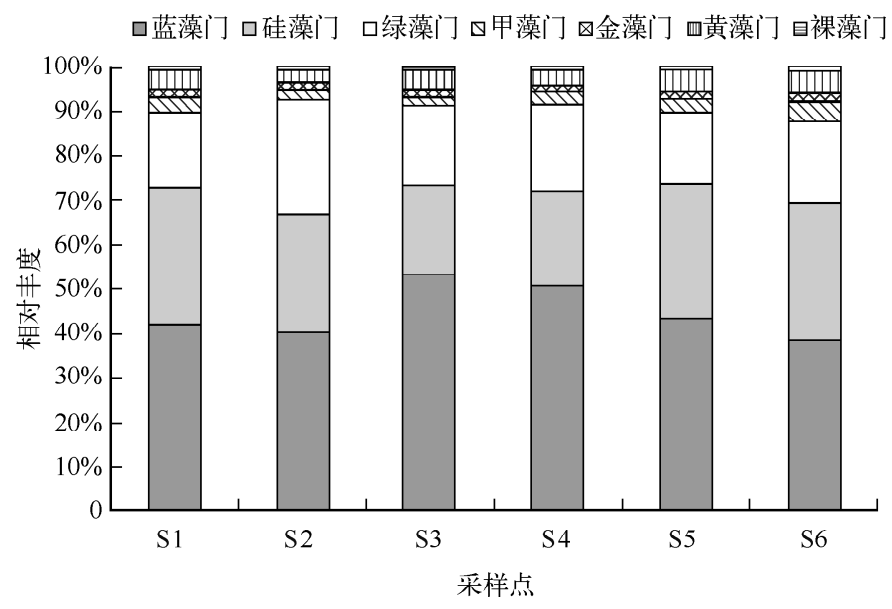

图 2 湖光岩玛珥湖浮游植物群落结构组成

Fig. 2 Phytoplankton community composition of the Huguangyan Maar Lake

\section{2 氮吸收特征}

2.2 .1 比吸收速率与绝对吸收速率 氮吸收实验结果表明, 浮游植物群落对铵态氮、硝态氮、尿素态氮的比吸 收速率 $(V)$ 分别为 $0.076 、 0.013 、 0.018 \mathrm{~h}^{-1}$, 对铵态氮的比吸收速率约为硝态氮的 5.8 倍, 约为尿素态氮的 4.2 倍. 浮游植物群落对铵态氮、硝态氮、尿素态氮的绝对吸收速率 $(\rho)$ 分别为 $0.211 、 0.034 、 0.043 \mu \mathrm{mol} /(\mathrm{L} \cdot \mathrm{h})$, 浮游植物以铵态氮吸收占主导. 湖光岩玛珥湖浮游植物对 3 种氮的比吸收速率与绝对吸收速率均表现为铵 态氮 > 尿素态氮 > 硝态氮.

2.2 .2 相对优先指数与周转时间 湖光岩玛珥湖浮游植物氮吸收相对优先指数 $(R P I)$ 是铵态氮 $>$ 尿素态氮 $>$ 硝态氮, 分别为 $2.907 、 1.192 、 0.190$, 表明浮游植物群落优先吸收铵态氮, 其次为尿素态氮, 最后为硝态氮. 湖光 岩玛珥湖浮游植物群落对铵态氮、硝态氮、尿素态氮的吸收周转时间 ( TT) 分别为 3.72、57.03、9.07 h, 表明湖 光岩玛珥湖浮游植物对铵态氮的吸收周转快于尿素态氮和硝态氮. 3 种溶解态氮的平均周转时间为 23.27 h.

\section{$2.3 \delta^{15} \mathrm{~N}$ 的变化特征}

$\delta^{15} \mathrm{~N}$ 为样品中 $\mathrm{N}$ 元素稳定同位素比值与标准物 (大气) 相应比值的千分偏差 ${ }^{[24]}$. 原位挂瓶 $4 \mathrm{~h}$ 后, 分别 对 3 种溶解态氮在不同 ${ }^{15} \mathrm{~N}$ 示踪剂浓度条件下实验组样品的 $\delta^{15} \mathrm{~N}$ 进行分析. 数据分析使用 SPSS 17.0 统计 软件, 根据 Duncan 多重比较, 使用单因素方差分析 ( ANOVA) 进行检验. 结果表明, 在 $4 \mathrm{~h}$ 的 ${ }^{15} \mathrm{~N}$ 富集挂瓶培 养实验后, 浮游植物样品中 $\delta^{15} \mathrm{~N}$ 值远远高于初始浓度 ${ }^{15} \mathrm{~N}$ 的 $\delta^{15} \mathrm{~N}$ 值, 表明浮游植物可以吸收 ${ }^{15} \mathrm{~N}$ 分子 (图 $3)$. 在 3 组实验中, 在添加不同 ${ }^{15} \mathrm{~N}$ 示踪剂浓度的条件下, 挂瓶培养 $4 \mathrm{~h}$ 后, 浮游植物的 $\delta^{15} \mathrm{~N}$ 值差异显著 $(P<$ 0.05 ) (图 3), 随着 ${ }^{15} \mathrm{~N}$ 示踪剂添加浓度的升高, 浮游植物细胞富集 $\delta^{15} \mathrm{~N}$ 值升高. 添加 ${ }^{15} \mathrm{~N}$ 底物浓度为 $10 \mu \mathrm{mol} / \mathrm{L}$ 时, 3 种 ${ }^{15} \mathrm{~N}$ 底物的浮游植物 $\delta^{15} \mathrm{~N}$ 均达到最大, 并且 $\delta^{15} \mathrm{~N}\left(\mathrm{NH}_{4}^{+}\right)$达到 $11285.3 \% 0$, 是 $\delta^{15} \mathrm{~N}\left(\mathrm{NO}_{3}^{-}\right)$的 
26.4 倍. 湖光岩玛珥湖的浮游植物群落可以利用铵态氮、硝态氮、尿素态氮, 而且对铵态氮的吸收富集显著 高于尿素态氮和硝态氮.

\section{4 浮游植物对溶解态氮吸收动力学特征}

湖光岩玛珥湖浮游植物群落对不同形态氮素的吸收速率均随 ${ }^{15} \mathrm{~N}$ 底物浓度的增加而增大, 并逐渐趋于 饱和 (图 4). 对氮营养盐的吸收速率与其初始浓度之间的关系符合 Michaelis-Menten 方程 $V=V_{\text {max }} \cdot S /\left(K_{\mathrm{S}}+\right.$ $S)$. 经 Lineweaver-Burk 作图法线性回归求得 $V_{\max }$ 和 $K_{\mathrm{S}}$. 浮游植物群落对铵态氮的最大比吸收速率为 $2.943 \mathrm{~h}^{-1}$,
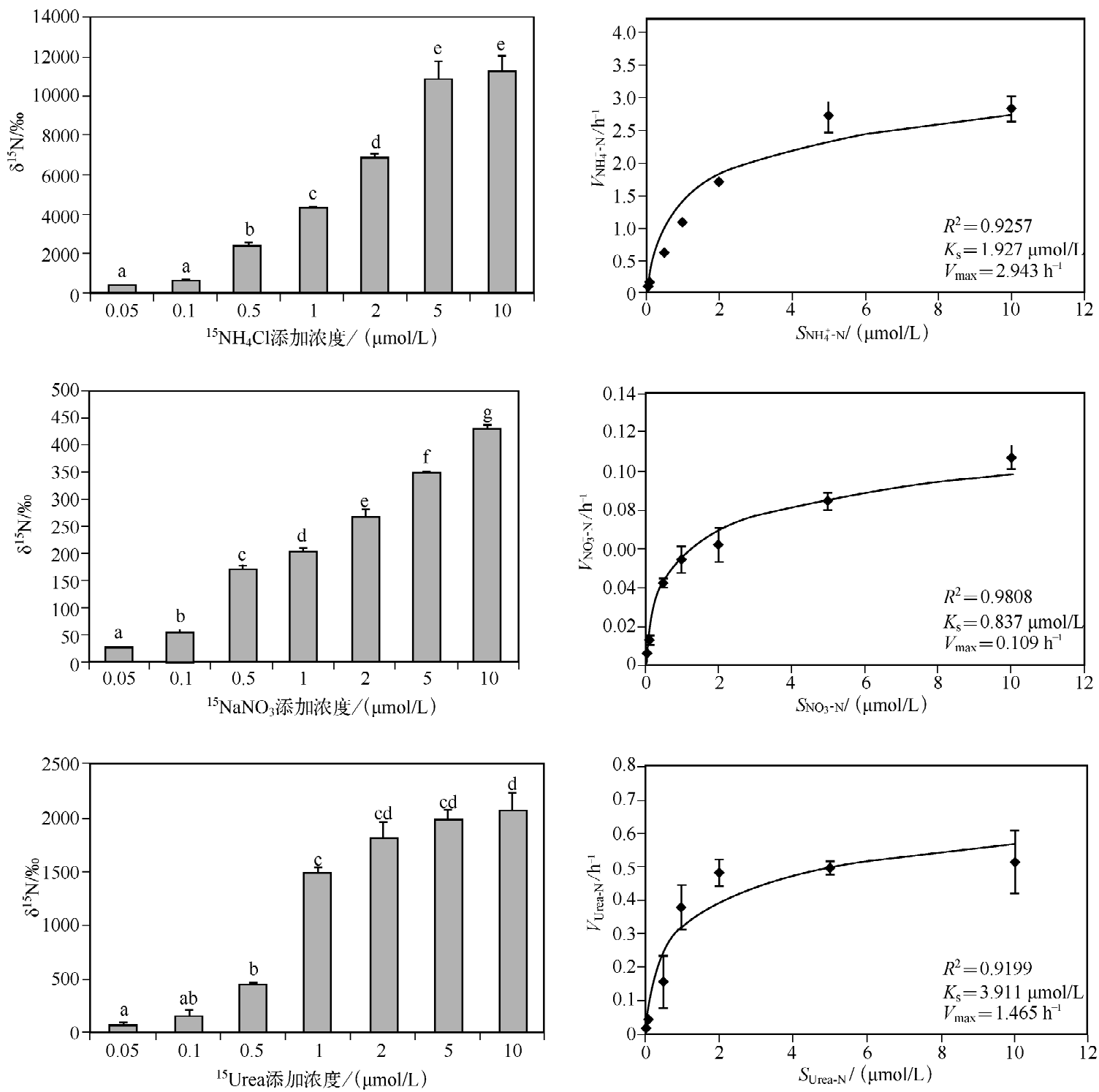

图 3 不同 ${ }^{15} \mathrm{~N}$ 底物和不同浓度条件下, 挂瓶 $4 \mathrm{~h}$ 实验后 浮游植物 $\delta^{15} \mathrm{~N}$ 值( 各组间字母不同表示差异显著)

Fig. 3 Comparison of $\delta^{15} \mathrm{~N}$ values of phytoplankton after the experiment when different substrate forms and concentrations of ${ }^{15} \mathrm{~N}$ were added

图 4 湖光岩玛珥湖浮游植物群落氮吸收动力学曲线

Fig. 4 Nitrogen uptake kinetic curves for phytoplankton in the Huguangyan Maar Lake 
显著高于硝态氮和尿素态氮; 浮游植物群落对 3 种溶解态氮的亲和力 $\left(1 / K_{\mathrm{S}}\right)$ 表现为硝态氮 $>$ 铵态氮 $>$ 尿素 态氮. 湖光岩玛珥湖浮游植物群落对铵态氮具有最大的吸收潜力, 同时对硝态氮具有一定的亲和力, 具备利 用硝态氮的能力 (图 4).

\section{3 讨论}

\section{1 不同形态氮吸收速率的比较}

铵态氮是浮游植物最喜好的氮形态, 因为与其它形态氮相比, 吸收 $\mathrm{NH}_{4}^{+}$所消耗的能量最少 ${ }^{[7]}$. 浮游植 物细胞可以获得各种形态的含氮分子, 含氮分子进人细胞膜后会还原为 $\mathrm{NH}_{4}^{+}$并结合到氨基酸碳链上; 在外 部 $\mathrm{NH}_{4}^{+}$浓度小于 $1 \mu \mathrm{mol} / \mathrm{L}$ 时, 浮游植物细胞膜上存在 $\mathrm{NH}_{4}^{+}$转运蛋白, 所以 $\mathrm{NH}_{4}^{+}$可以透过细胞膜 ${ }^{[25]}$. 硝态 氮通过主动运输进人浮游植物细胞, 在硝酸盐还原酶和亚硝酸盐还原酶的作用下先还原为亚硝酸盐, 然后 还原为 $\mathrm{NH}_{4}^{+}$; 而尿素分子需酶解为 2 个 $\mathrm{NH}_{4}^{+}$和 1 个 $\mathrm{CO}_{2}$ 分子, 再被浮游植物细胞利用 ${ }^{[26]}$. 浮游植物对溶解 态氮的吸收效率受控于其 $n t c A$ 基因编码的一种调控蛋白 ${ }^{[27-28]}$, 当环境 $\mathrm{NH}_{4}^{+}$浓度大于 $1 \mu \mathrm{mol} / \mathrm{L}$ 时会抑制 $n t c$ $A$ 基因的表达 ${ }^{[29]}$, 在缺乏 $\mathrm{NH}_{4}^{+}$的条件下 $n t c A$ 基因编码的调控蛋白可以促进硝酸盐还原酶、亚硝酸盐还原 酶和脲酶基因的表达 ${ }^{[25,27]}$. 因此,一般在 $\mathrm{NH}_{4}^{+}$浓度相对较低的情况下浮游植物吸收 $\mathrm{NH}_{4}^{+}$的速率均超过其 他几种溶解态氮, 当 $\mathrm{NH}_{4}^{+}$浓度大于 $1 \mu \mathrm{mol} / \mathrm{L}$ 时浮游植物对其它形态氮的吸收也会出现偏好的现象 ${ }^{[30]}$.

经测定, 湖光岩玛珥湖的环境 $\mathrm{NH}_{4}^{+}$浓度为 $0.735 \mu \mathrm{mol} / \mathrm{L}$, 小于 $1 \mu \mathrm{mol} / \mathrm{L}$, 湖光岩玛珥湖浮游植物群落 对 $\mathrm{NH}_{4}^{+}$的吸收速率最高, 其对 3 种氮的绝对吸收速率顺序为: $\rho\left(\mathrm{NH}_{4}^{+}\right)>\rho(\mathrm{Urea})>\rho\left(\mathrm{NO}_{3}^{-}\right)$, 这与 $\mathrm{Smith}$ 湖、Okeechobee 湖、Biwa 湖中浮游植物对铵态氮、硝态氮和尿素态氮吸收情况的研究结果相符 ${ }^{[9-10,31]}$, 表明湖 光岩玛珥湖春季浮游植物群落对铵态氮的吸收速率最高, 铵态氮是该湖泊浮游植物吸收氮的主要形态.

\section{2 不同形态氮的吸收选择性}

浮游植物对不同形态氮的吸收优先性与浮游植物群落结构有关, 氮的存在形态也会影响浮游植物的群 落结构 ${ }^{[32-33]}$. McCarthy 等 ${ }^{[34]}$ 提出了 RPI 的概念, 用于表征哪一种氮源是浮游生物优先利用的形式. 相对优先 指数等于 1 , 表明浮游生物对该营养盐的吸收正比于其提供量; 相对优先指数大于或小于 1 , 表明相对于提供 量而言, 浮游生物具有较快或较慢的吸收速率 ${ }^{[11]}$. Wheeler 等 ${ }^{[35]}$ 证明铵态氮的吸收是水域生态系统氮吸收 的主要部分之一, 这与原核生物的生命活动密切相关. 本研究结果表明, 湖光岩玛珥湖浮游植物群落组成 中, 原核生物中的蓝藻为主要组成部分, 占 $44.68 \%$, 其绝对优势种为水华微囊藻与铜绿微囊藻. 湖光岩玛珥 湖浮游植物对铵态氮吸收的相对优先指数高, 表明除了吸收铵态氮所消耗能量最少的内因之外, 该湖泊中 以蓝藻门为主的浮游植物群落组成对其也有一定影响. 湖光岩玛珥湖浮游植物群落对铵态氮吸收的相对优 先指数大于硝态氮和尿素态氮, 铵态氮是湖光岩玛珥湖浮游植物优先利用的氮源. 硝态氮的相对优先指数 相对较低而周转时间较长, 硝态氮是湖光岩玛珥湖浮游植物群落吸收的一种次要氮源. 因此, 铵态氮、硝态 氮、尿素态氮都是湖光岩玛珥湖浮游植物可吸收的氮源, 而浮游植物更偏好铵态氮.

\section{3 吸收动力学}

浮游生物营养吸收动力学的研究目的主要在于获得浮游生物对营养盐吸收方面的有关参数, 并通过这 些参数对浮游生物的生态习性和特点作出推断和阐释, 从而了解它们在生态系统中的作用和功能 ${ }^{[13]}$. Michaelis-Menten 方程是表示一个酶促反应的起始速度与底物浓度关系的速度方程 ${ }^{[36]}$. Suttle 等 ${ }^{[37]}$ 的研究表 明, 浮游植物对氮的吸收过程可用 Michaelis-Menten 方程来描述. $V_{\text {max }}$ 表征细胞对营养离子的吸收潜力, $K_{\mathrm{S}}$ 表 征细胞对营养离子的亲和力 ${ }^{[38]}$.

本实验中, 湖光岩玛珥湖浮游植物对铵态氮、硝态氮、尿素态氮的吸收动力学符合 Michaelis-Menten 方 程 (图 4). 铵态氮的 $V_{\max }$ 高于尿素态氮和硝态氮, 表现出浮游植物群落对铵态氮具有较高的吸收潜力. 铵态 氮、尿素态氮的 $K_{\mathrm{s}}$ 分别约为其环境浓度的 2.6 倍和 11.5 倍, 而硝态氮的 $K_{\mathrm{s}}$ 低于其环境浓度, 这个结果与 $\mathrm{Gu}$ 等 ${ }^{[9]}$ 对 Smith 湖的研究结果相似. 湖光岩玛珥湖浮游植物群落对硝态氮的 $K_{\mathrm{S}}$ 最小, 说明在环境氮浓度较低 的条件下浮游植物细胞对硝态氮具有一定的亲和力, 具备利用硝态氮的能力.

\section{4 湖光岩玛珥湖溶解态氮吸收的重要性}

氮是湖泊水体的营养限制因子 ${ }^{[39-41]}$. 湖泊生态系统中氮的生物地球化学循环是生物圈物质能量循环的 
重要组成部分, 浮游植物对溶解态氮的吸收、转化是湖泊中氮生物循环的关键环节. 本研究结果表明, 湖光 岩玛珥湖中铵态氮、硝态氮、尿素态氮都是浮游植物可吸收的氮源, 浮游植物对这几种氮的吸收动力学曲线 均可通过 Michaelis-Menten 方程进行描述, 并且浮游植物对铵态氮表现出高吸收速率, 更偏好利用铵态氮. 浮游植物对溶解态氮的吸收转化作用一定程度上降低了水体氮浓度, 参与湖泊中氮素的生物循环, 对湖泊 水体自净起了重要的生物学作用, 另外,有关浮游植物氮吸收的深人研究也有助于进一步丰富湖泊浮游植 物的营养理论.

致谢: 古滨河在同位素样品测定和实验方法上提供的重要帮助,刘新宇、曾园园、梁辉健、李新宇等协助完成 采样工作,在此向他们表示衰心的感谢.

\section{4 参考文献}

[ 1 ] 匡欢传,周浩达,胡建芳等. 末次盛冰期和全新世大暖期湖光岩玛琟湖沉积记录的正构烷烃和单体稳定碳同位素 分布特征及其古植被意义. 第四纪研究,2013,33(6):1222-1233.

[2] 曾 巾,杨柳燕, 肖 琳等. 湖泊氮素生物地球化学循环及微生物的作用. 湖泊科学, 2007,19(4):382-389.

[ 3 ] Yang L, Chang HT, Huang MNL. Nutrient removal in gravel-and soil-based wetland microcosms with and without vegetation. Ecological Engineering, 2001, 18(1):91-105.

[ 4 ] Dai R, Liu H, Qu J et al. Effects of amino acids on microcystin production of the Microcystis aeruginosa. Journal of Hazardous Materials, 2009, 161(2):730-736.

[5] 韩博平,林旭钿,李 铁. 广东省大中型水库富营养化现状与防治对策研究. 北京:科学出版社,2003.

[ 6 ] Berman T. Urea in the waters of lake kinneret (Sea of Galilee). Limnology and Oceanography, 1974, 19(6):977-980.

[ 7 ] 杨 柳,章 铭,刘正文. 太湖春季浮游植物群落对不同形态氮的吸收. 湖泊科学,2011,23(4):605-611.

[ 8 ] Berman T. Dissolved organic nitrogen utilization by an Aphanizomenon bloom in Lake Kinneret. Journal of Plankton Research, 1997,19 ( 5 ) : :577-586.

[ 9 ] Gu BH, Alexander V. Dissolved nitrogen uptake by a cyanobacterial bloom (Anabaena flos-aquae) in a subarctic lake. Applied and Environmental Microbiology, 1993, 59(2):422-430.

[10] Gu BH, Havens KE, Schelske CL et al. Uptake of dissolved nitrogen by phytoplankton in a eutrophic subtropical lake. Journal of Plankton Research, 1997, 19(6):759-770.

[11] 陈 敏,黄奕普,邱雨生. 白令海盆氮吸收速率的同位素示踪. 自然科学进展,2007,7(12):1672-1684.

[12］李清雪. 渤海湾浮游生物氮吸收动力学研究. 河北建筑科技学院学报,2001,18(2):1-4.

[13] 焦念志. 海洋浮游生物氮吸收动力学及其粒级特征. 海洋与湖沼, 1995,26(2):191-198.

[14] 金相灿, 屠清瑛. 湖泊富营养化调查规范. 北京: 中国环境科学出版社,1990.

[15］杨佩丽,余佳红, 曹 云.二乙酰一肪一安替比林分光光度法测定游泳池水中尿素的方法改进与探讨. 河南预防医 学杂志, $2010,21(6): 419-420$.

[16] 蒋岳文. 靛酚蓝分光光度法测定海水中的氨氮. 海洋环境科学,1990,9(1):193-196.

[17] 赵 文. 水生生物学. 北京:中国农业出版社,2005:509.

[18] 胡鸿均,魏印心. 中国淡水藻类. 北京:科学出版社,2006.

[19] Dugdale RC, Goering JJ. Uptake of new and regenerated forms of nitrogen in primary productivity. Limnology and Oceanography, 1967, 12(2):196-206.

[20] Dugdale RC, Wilkerson FP. The use of ${ }^{15} \mathrm{~N}$ to measure nitrogen uptake in eutrophic oceans; experimental considerations. Limnology and Oceanography, $1986, \mathbf{3 1}(4)$ : 673-689.

[21] Gu BH, Alexander V. Seasonal variations in dissolved inorganic nitrogen utilization in a subarctic Alaska lake. Archiv fur Hydrobiologie, 1993, 126(3):273-288.

[22] Chaffin JD, Bridgeman TB. Organic and inorganic nitrogen utilization by nitrogen-stressed cyanobacteria during bloom conditions. Journal of Applied Phycology, 2014,26(1):1-11.

[23] 陈 静, 蒋万祥, 王洪凯. 微山湖典型水域营养盐分布及富营养化评价. 中国农学通报,2011,27(3):421-424.

[24] 黄翔鹄,刘 梅,周美华等. 波吉卵囊藻对养殖水体溶解态氮吸收规律的研究. 渔业现代化, 2012,3:9.

[25] Herrero A, Muro-Pastor AM, Flores E. Nitrogen control in cyanobacteria. Journal of Bacteriology, 2001, 183 (2): $411-425$. 
[26] Finlay K, Patoine A, Donald DB et al. Experimental evidence that pollution with urea can degrade water quality in phosphorus-rich lakes of the Northern Great Plains. Limnology and Oceanography, 2010, 55(3) :1213-1230.

[27] Frias JE, Mérida A, Herrero A et al. General distribution of the nitrogen control gene ntcA in cyanobacteria. Journal of Bacteriology, 1993, 175(17):5710-5713.

[28] Vega-Palas MA, Flores E, Herrero A. NtcA, a global nitrogen regulator from the cyanobacterium Synechococcus that belongs to the Crp family of bacterial regulators. Molecular Microbiology, 1992, 6(13):1853-1859.

[29] Lindell D, Post AF. Ecological aspects of ntcA gene expression and its use as an indicator of the nitrogen status of marine Synechococcus spp. Applied and Environmental Microbiology, 2001, 67 (8) :3340-3349.

[30] Dortch Q. The interaction between ammonium and nitrate uptake in phytoplankton. Marine Ecology Progress Series, 1990, 61 ( 1 ) : :183-201.

[31] Ishida N, Mitamura O, Nakayama M. Seasonal variation in biomass and photosynthetic activity of epileptic algae on a rock at the upper littoral area in the north basin of Lake Biwa. Japan Limnology, 2006, 7(3) :175-183.

[32 ] Blomqvist P, Petterson A, Hyenstrand P. Ammonium-nitrogen: a key regulatory factor causing dominance of non-nitrogenfixing cyanobacteria in aquatic systems. Archiv fiir Hydrobiologie, 1994, 132(2) :141-164.

[33] Dai GZ, Shang JL, Qiu BS. Ammonia may play an important role in the succession of cyanobacterial blooms and the distribution of common algal species in shallow freshwater lakes. Global Change Biology, 2012, 18(5) :1571-1581.

[34] McCarthy JJ, Taylor WR, Taft JL. Nitrogenous nutrition of the plankton in the Chesapeake Bay. 1. Nutrient availability and phytoplankton preferences. Limnology and Oceanography, 1977, 22 (6) :996-1011.

[35] Wheeler PA, Kirchman DL. Utilization of inorganic and organic nitrogen by bacteria in marine systems. Limnology and Oceanography, 1986,31(5):998-1009.

[36] Michaelis L, Menten ML. Die kinetik der invertinwirkung. Biochem z, 1913, 49(333-369) :352.

[37] Suttle CA, Harrison PJ. Ammonium and phosphate uptake rates, N: P supply ratios, and evidence for N and P limitation in some oligotrophic lakes. Limnology and Oceanography, $1988: 186-202$.

[38] Kim S, Park H, Choi W. Comparative study of homogeneous and heterogeneous photocatalytic redox reactions: $\mathrm{PW}_{12} \mathrm{O}_{40}^{3-}$ vs $\mathrm{TiO}_{2}$. The Journal of Physical Chemistry B, 2004, 108(20):6402-6411.

[39] Justin DC, Thomas BB, Darren LB. Nitrogen constrains the growth of late summer Cyanobacterial blooms in Lake Erie. Advances in Microbiology, 2013, 3:16.

[40] Jeppesen E, Soendergaard M, Jensen JP et al. Lake responses to reduced nutrient loading-an analysis of contemporary long-term data from 35 case studies. Freshwater Biology, 2005, 50(10) :1747-1771.

[41] Xu H, Paerl HW, Qin B et al. Nitrogen and phosphorus inputs control phytoplankton growth in eutrophic Lake Taihu, China. Limnology and Oceanography, 2010, 55(1):420. 